\title{
ФИЗИКО-МЕХАНИЧЕСКИЕ СВОЙСТВА КРУПНООБЛОМОЧНОГО МАТЕРИАЛА ГРАВИЙНО-ГАЛЕЧНЫХ ОТЛОЖЕНИЙ ЭСТОНСКОЙ ССР
}

Гравийно-галечные, преимущественно флювиогляциальные отложения - важный местный строительный материал, добыча которого в республике ежегодно расширяется. Качество, а следовательно, и возможности пприменения гравия и гравийно-галечной смеси тесно связаны с физико-механическими свойствами крупнообломочной фракции этих отложений. Основные физико-механичеокие свойства отложений определяются дробимостью при сжатии в цилиндре, истираемостью в полочном барабане и морозостойкостью. В литературе эти вопросы освещены слабо, имеются лишь некоторые обобщающие данные (Кӓрра, 1934; Lepp, Meschin, 1971; Раукас, 1978).

Для характеристики физико-механических свойств крупнообломочного материала и районирования гравийно-галечных отложений Эстонской ССР нами иопользованы результаты многолетних исследований, проведенных в Центральной дорожно-строительной лабораторни Министерства автотранопорта и шоссейных дорог Эстонской ССР. В настоящей работе использованы данные 123 анализов дробимости при сжатии в цилиндре из 62 месторождений, 199 анализов истираемости в полочном барабане из 87 месторождений и 207 анализов морозостойкости из 71 месторождения. Испытанию подвергали галечные фракции отложений.

Дробимость при сжатии определяют в цилиндре диаметром 150 мм под давлением 20 тс. После сжатия пробу просеивают через контрольное сито, определяют потери массы в процентах, устанавливают марку дробимости в цилиндре (Др) (табл. 1, 2; ГОСТ 8268-74). Гравий марок Др8, Др12 и Др16 должен содержать не более $10 \%$ зерен слабых пород (сланцы, песчаники, глинистые известняки, домериты), гравий марки Др24-не более $15 \%$ по массе.

Истираемость галечника в полочном барабане определяют при его использовании в строительстве автомобильных дорог, употребляя для этого полочный барабан с чугунными шарами, который вращается со скоростью $30-33$ об/мин. Марка истираемости (И) устанавливается по потере пробы в массе после испытания (табл. 3, ГОСТ 8268-74).

Морозостойкость гравия и галечника (нли щебня) определяют попеременным замораживанием и оттаиванием пробы. После 15 и каждых последующих 25 циклов попеременного замораживания и оттаивания навеску галечника высушивают, просеивают через сито, на котором проба полностью оставалась перед испытанием, и взвешивают остаток на сите. Если потеря массы превысила допускаемый предел, испытания прекращают и показатель морозостойкости (Мрз) данной пробы характеризуют предыдущим числом циклов замораживания и оттаивания. Допускаемый предел потери массы для марок Мрз15 и Мрз25 10, для марок Мрз50, Мрз100 и больше - $5 \%$ (ГОСТ 8268-74). 


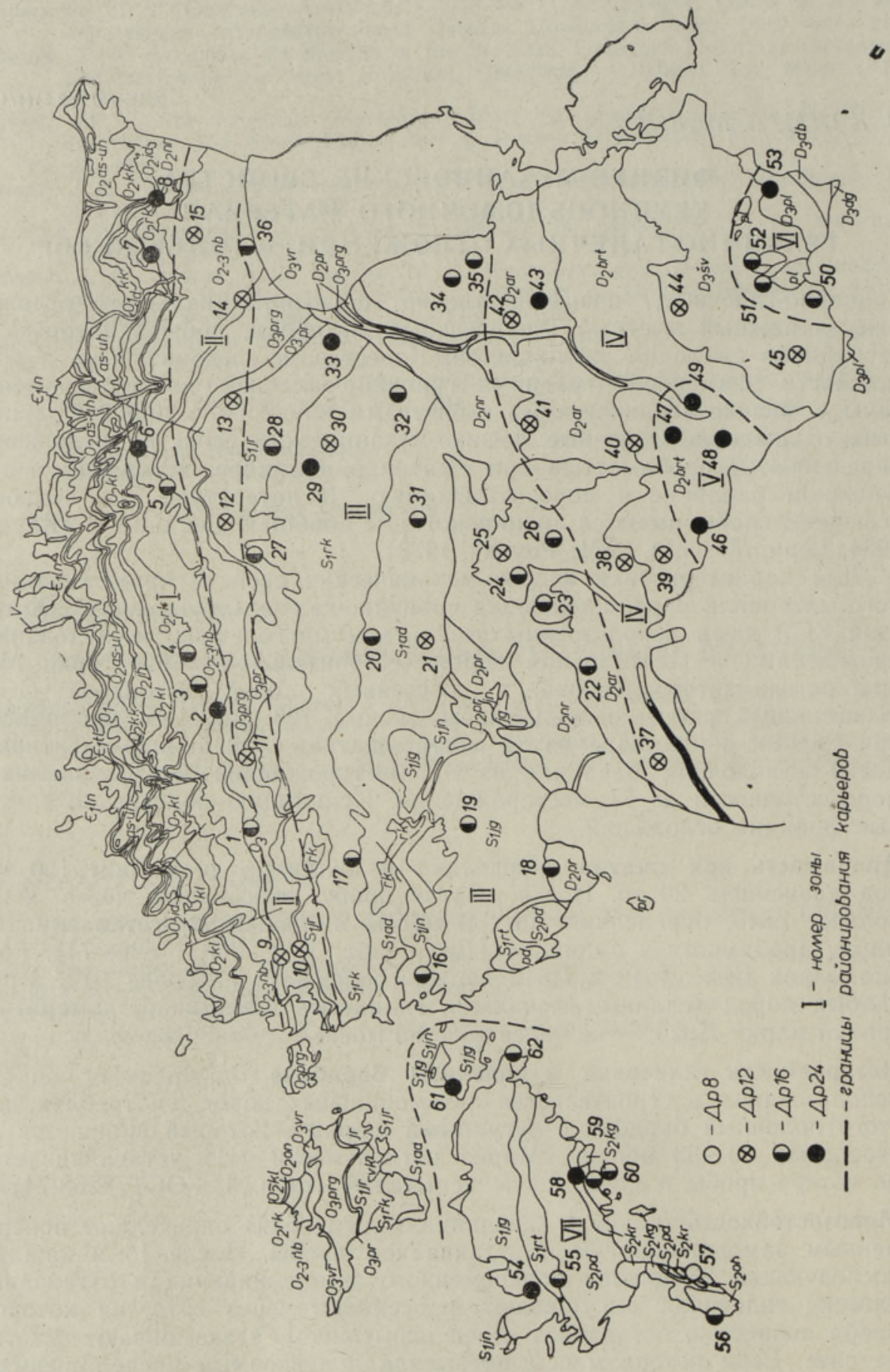


Рис. 1. Расположение и районирование изученных карьеров гравийно-галечных отложений по дробимости крупнообломочной фракции при сжатии в цилиндре (на фоне геологической карты). Карьеры: 1 - Мутсу, 2 - Нырава, 3 - Мардимяэ, 4 - Вахелаане, 5 - Лазила, 6 - Раквере, 7 - Калина, 8 - Рауди, 9 - Кеэдика, 10 - Арду, 11 - Сели, 12 - Мяэотса, 13 - Вескимяэ, 14 - Тудулинна, $15-$ Ийзаку, 16 - Кинкси, 17 - Луйсте, 18 - Потсепа, 19 - Лавассааре, 20 - Кыльтси, 21 - Круузимяэ, 22 - Тылла, 23 - Мянни, 24 - Вяльгита, 25 - Саарепеэди, 26 - Супсимари, 27 - Яллимяэ, 28 - Таммнку, 29 - Пийбе, 30 - Луйге, 31 Сулуствере, 32 - Пикамяэ, 33 - Кынну, 34 - Постова II, 35 - Вяльги, 36 Выхма, 37 - Аруоя, 38 - Мяэкюла, 39 - Ванамыйза, 40 - Кооза III, 41 Поости, 42 - Кабина, 43 - Сууремяэ, 44 - Сульби, 45 - Лоссимяэ, 46 - Холдре, 47 - Принги, 48 - Сийму, 49 - Ресту, 50 - Краби, 51 - Ногопалу, 52 Пюссапалу, 53 - Кюньдя, 54 - Абула, 55 - Варкья, 56 - Тюрью, 57 - Вийеристи, 58 - Рео, 59 - Ванамыйза, 60 - Касти, 61 - Когува, 62 - Кюбассааре.

Дробимость при сжатии в цилиндре. На территории Әстонской ССР преобладает гравийно-галечный материал марки Др16. Практически отсутствуют высококачественные отложения марки Др8. По марке дробимости отложения 62 месторождений гравийно-галечного материала Эстонии распределяются следующим образом:

Таблица 1

\begin{tabular}{l|c|c|c}
\hline $\begin{array}{c}\text { Марка } \\
\text { дробимости }\end{array}$ & $\begin{array}{c}\text { Потеря массы } \\
\text { после испыта- } \\
\text { ния, \% }\end{array}$ & $\begin{array}{c}\text { Количество } \\
\text { изученных } \\
\text { месторождений }\end{array}$ & $\begin{array}{c}\text { Распределение } \\
\text { изученных } \\
\text { месторождений, } \\
\%\end{array}$ \\
\hline Др8 & до 8 & 1 & 1,6 \\
Др12 & $\begin{array}{c}12-12 \\
\text { Др16 }\end{array}$ & 18 & 29,0 \\
Др24 & $16-24$ & 28 & 45,2 \\
& Bcero: & 62 & 24,2 \\
\cline { 2 - 4 } & & & 15 \\
\hline
\end{tabular}

На схеме расположения изученных карьеров (рис. 1) выделяется несколько зон и районов по различным показателям дробимости: В Северо-Эстонской зоне отложений с относительно низкими показателями дробимости (I) доминирует материал марки Др16 или Др24. К этой зоне относятся карьеры Мусту (рис. 1, 1), Нырава (2), Мардимяэ (3), Вахелаане (4), Лазила (5), Раквере (6), Калина (7) и Рауди (8). Южная граница зоны расположена в ее западной и средней частях, несколько километров севернее от северной границы выходов пиргуокого горизонта, а в восточной части проходит по линии Виру-Яагупи-Йуга. В галечной фракции флювиогляциальных отложений Северо-Эстонского плато сильно преобладают $(60-90 \%)$ карбонатные обломки местного происхождения (Раукас, Ряхни, Мийдел, 1971). Следовательно, качество подстилающих ордовикских карбонатных пород в значительной мере определяет физико-механические свойства гравийно-галечных отложений. Дальность переноса галек исходной породы в водно-ледниковых потоках достигает $16-20$ км (Раукас, Ряхни, Мийдел, 1971). Таким образом, относительно низкие показатели дробимости гравийно-галечного материала в этой зоне обусловлены значительным содержанием в отложениях обломков сравнительно легко эродируемых карбонатных пород кукрузеского, идавереского, йыхвиского и кейлаского горизонтов. Обломки устойчивых известняков раквереского горизонта в расоматриваемых отложениях, по-видимому, составляют лишь небольшую часть.

$\mathrm{K}$ описанной зоне в южном направлении следует узкая полоса

3 ENSV TA Toimetised. G $4 \quad 1983$ 
отложений с хорошими (Дір12) показателями дробимости. Эта СевероЭстонская зона отложений марки Др12 (II) расположена в основном на выходах пиргуского и поркуниского торизонтов, а в восточной ее части - также на выходах юуруского и набалаского горизонтов. Сравнительно хорошие показатели дробимости в этой зоне объясняются главным образом тем, что гальки пород раквереского горизонта как более устойчивые переносятся на более значительные расстояния, чем мергелистые гальки оандуского или горючие сланцы кукрузеского горизонта и поэтому их влияние на качество гравийно-галечного материала появляется в среднем на $5-25$ км южнее выходов самого торизонта. Значительное содержание известняков раквереского горизонта среди карбонатного обломочного материала южнее выходов горизонта было отмечено ранее (Öpik, 1936).

В Средне-Эстонской зоне (III) преобладают отложения марки Др16. Эта зона приблизительно совпадает с выходами силурийских карбонатных пород и песчаников пярнуского, наровского и северной частью арукюлаского горизонтов среднего девона. Марки дробимости ниже оредней (Др24) встречаются в карьерах Пийе (рис. 1, 29) и Кынну (33), а выше средней (Др12) в карьерах Круузимяэ (21) и Луйге (30). В остальных 16 изученных месторождениях этого района определена марка Др16. Ни один горизонт подстилающих коренных пород этого района не отличается устойчивостью к экзогенным процессам. В южной части района качество отложений понижается из-за появления обломков девонских песчаников и алевролитов, содержание которых в северной части Сакалаской возвышенности местами доходит до $20-40 \%$.

Южно-Эстонская зона отложений марки Др12 (IV) расположена на выходах южной части арукюлаского, восточной части буртниекского и на выходах швянтойского торизонтов. На выходах песчаных девонских пород Южной Эстонии относительное содержание карбонатных обломков, как менее устойчивых, уменьшается, составляя в галечно-валунных фракциях 40-60\% (Раукас, 1978), и соответственно увеличивается относительное содержание более стойких кристаллических пород. Здесь качество отложений лучше, чем в Средне-Эстонской зоне, т. к. более слабые карбонатные и песчаные обломки истираются при транспортировке и увеличивается содержание кристаллического компонента. Гравийно-галечные отложения этой зоны сосредоточены преимущественно в камовых образованиях. Как отмечает А. Раукас (1978), девонские песчаники в отложениях флювиокамов Южной Эстонии встречаются изредка. Аномально низкими показателями дробимости (Др24) в описываемой зоне отличается месторождение Сууремяэ (43).

Валгаская низина и южные части Сакалаской и Отепяской возвышенностей образуют Валгаскую зону гравийно-галечных отложений марки Др24 (V). Низкокачественные отложения расположены здесь целиком на выходах песчаников и алевролитов буртниекското горизонта. К этой зоне относятся карьеры Холдре (46), Ресту (49), Принги (47) и Сийму (48).

Хааньяская зона (VI) отложений марки Др16 охватывает наивысшую часть Хааньяской возвышенности. Образцы на анализы отобраны из карьеров, расположенных близ северной траницы выходов карбонатных пород плявинского горизонта. Пока отсутствуют детальные петрографические анализы галечно-валунных фракций этих отложений, невозможно связать понижение их качества с расположением выходов неустойчивых мергелистых и глинистых доломитов и известняков в этом районе. Таким образом, причина понижения качества гравийно-галечного материала в последних двух районах остается пока неясной. 
На о-ве Саaремаa (VII) распространены гравийно-галечные отложения марки Др16 и Др24. Лишь галечник месторождения Вийеристи (57) удовлетворяет требованиям марки Др8. По всей территории острова гравийно-галечные, как и все плейстоценовые отложения, сильно переработаны водами Балтийского моря, несомненно, вызвавшего некоторое разрушение карбонатных пород, содержащих преимущественно (70-80\%) обломки местных разновидностей (Раукас, Ряхни, Мийдел, 1971), которые, кроме биогермных известняков яагарахуского горизонта, не отличаются устойчивостью к эрозионно-денудационным процессам.

Суммируя вышесказанное, следует отметить, что гравийно-галечные отложения Эстонской ССР в среднем по дробимости в цилиндре не отличаются от производимого в Эстонии карбонатного щебня, но превышают ппо качеству щебень из обогатительного остатка сланцевых шахт Северо-Восточной Эстонии (табл. 2).

Таблица 2

\begin{tabular}{l|c|c}
\hline \multicolumn{1}{c|}{ Название сырья } & $\begin{array}{c}\text { Потеря массы } \\
\text { после сжатия } \\
\text { в цилиндре, \% }\end{array}$ & $\begin{array}{c}\text { Марка } \\
\text { дробимости * }\end{array}$ \\
\hline Щебень карьера Анелема & $11-13^{* *}$ & 1000 \\
Щебень карьера Маарду & $15-19^{* *}$ & 600 \\
Щебень карьера Вазалемма & $15-24$ & 400,600 \\
Гранитный щебень о-ва Сааремаа & до 11 & 1200 \\
Щебень обогатительного остатка шахты «Виру» & $19-24^{* *}$ & 400 \\
Щебень обогатительного остатка шахты «Ахтм» & $19-24^{* *}$ & 400 \\
Щебень обогатительного остатка шахты «Там- & $19-24^{* *}$ & 400 \\
мику»
\end{tabular}

* Марка дробимости щебня при сжатии в цилиндре определяется по ГОСТ-у 8267-75.

** В среднем.

Истираемость галечника в полочном барабане. 87 изученных месторождений гравийно-галечных отложений Эстонской ССР распределяются по маркам истираемости следующим образом:

таблица 3

\begin{tabular}{|c|c|c|c|}
\hline $\begin{array}{c}\text { Марка } \\
\text { нстирае- } \\
\text { мости }\end{array}$ & $\begin{array}{c}\text { Потеря } \\
\text { массы после } \\
\text { испытання, } \\
\%\end{array}$ & $\begin{array}{l}\text { Коли- } \\
\text { чество } \\
\text { место- } \\
\text { рож- } \\
\text { дений }\end{array}$ & $\begin{array}{c}\text { Распределе- } \\
\text { ние изучен- } \\
\text { ных место- } \\
\text { рождений, } \\
\%\end{array}$ \\
\hline $\begin{array}{l}\text { И-I } \\
\text { И-II } \\
\text { H-III } \\
\text { И-IV }\end{array}$ & $\begin{array}{l}\text { до } 20 \\
20-30 \\
30-40 \\
40-50\end{array}$ & $\begin{array}{r}1 \\
56 \\
25 \\
5\end{array}$ & $\begin{array}{r}1,1 \\
64,4 \\
28,7 \\
5,8\end{array}$ \\
\hline & Bcero: & 87 & 100,0 \\
\hline
\end{tabular}

\begin{tabular}{l|c|c}
\hline $\begin{array}{c}\text { Название } \\
\text { карьера }\end{array}$ & $\begin{array}{c}\text { Коли- } \\
\text { чество } \\
\text { ана- } \\
\text { лизов }\end{array}$ & $\begin{array}{c}\text { Потеря массы, } \\
\%\end{array}$ \\
\hline Потсепа & 7 & $\frac{23,2-30,0}{27,8}$ \\
Реола & 5 & $\frac{28,1-34,2}{30,6}$ \\
Малева & 4 & $\frac{21,2-21,9}{21,6}$ \\
Абула & 5 & $\frac{24,8-29,0}{27,2}$ \\
Калда & 8 & $\frac{20,2-23,8}{22,1}$
\end{tabular}

Из этого видно, что добываемый в Эстонской ССР гравий преимущественно соответствует требованиям марок И-II и И-III. Из 32 месторождений взяты пробы для параллельных анализов дробимости при 


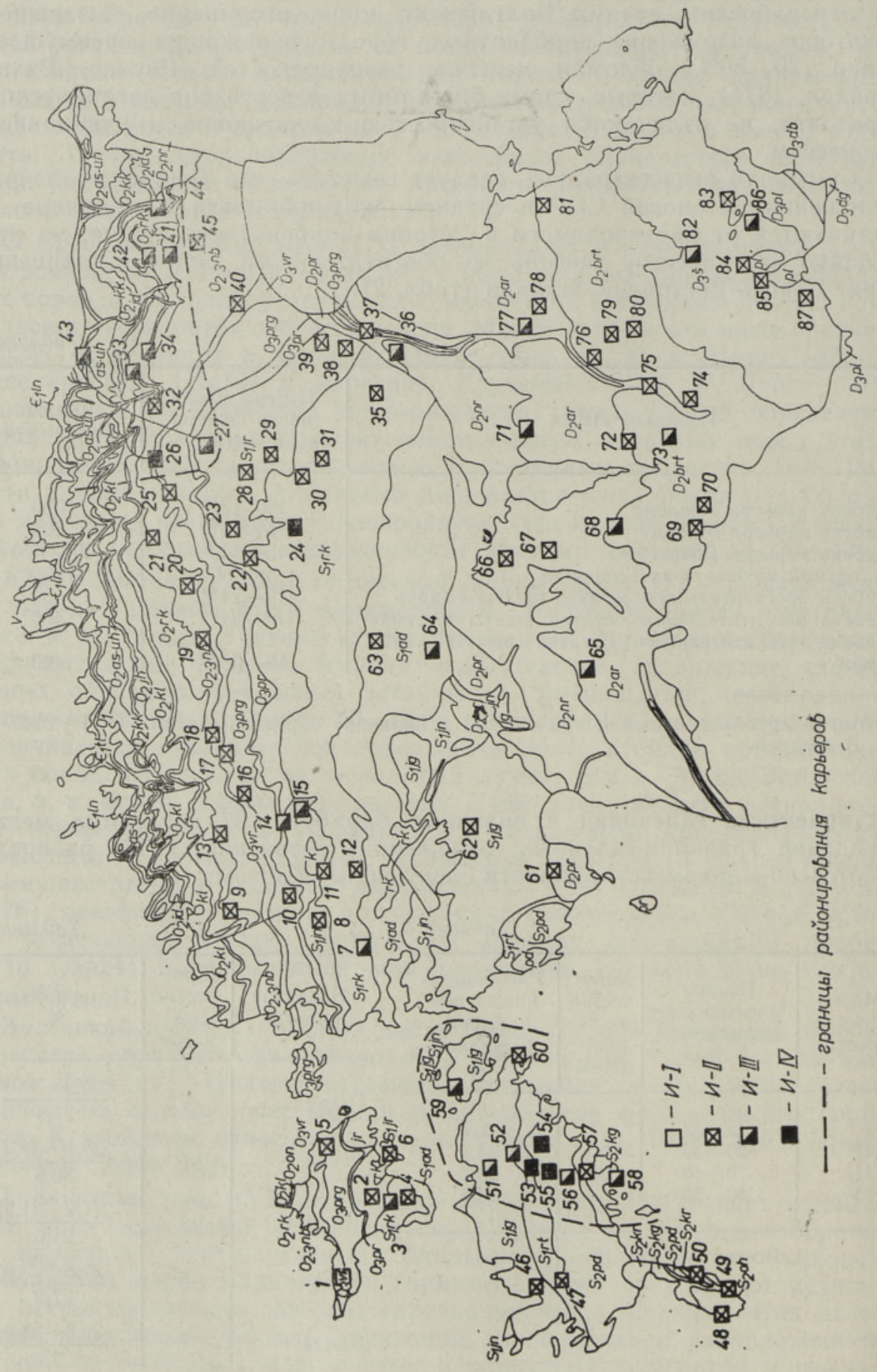


Рис. 2. Схема расположения и районирования изученных карьеров гравийно-галечных отложений по истираемости крупнообломочной фракции в полочном барабане (на фоне геологической карты). Карьеры: $I$ - Суурепси, 2 - Мяннамаа, 3 - Лигема, 4 - Муда, 5 - Партси, 6 - Кассари, 7 - Рыуде, 8 - Каопалу, 9 - Яннимаа, 10 - Калда, 11 - Меэритсе, 12 - Луйсте, 13 - Руйла II, 14 - Кюкита, 15 Орава, 16 - Амбузе, 17 - Нурга, $18-$ Пахкла, $19-$ Куриссааре, $20-$ Малева, 21 - Ванамыйза, 22 - Яллимяэ, 23 - Мяэотса, 24 - Калитса, 25 - Лазила, 26 - Инью, 27 - Уникюла, 28 - Вао, 29 - Таммику, 30 - Пийбе, 31 - Луйге, 32 - Сае, 33 - Турбамяэ, 34 - Похлаару, 35 - Пикамяэ, 36 - Вайдавере, 37 Отса, 38 - Сиргувере, 39 - Кынну, 40 - Тудулннна, 41 - Мяэтагузе, 42 - Калина, 43 - Азери, 44 - Рауди, 45 - Ийзаку, 46 - Абула, 47 - Варкья, $48-$ Тюрью, 49 - Мынту, 50 - Вийеристи, 51 - Лейзи, 52 - Пика, 53 - Раэкюла, 54 - Уссиотса, 55 - Кыльяла, 56 - Пихтла-Қынну, 57 - Рео, 58 - Касти, 59 Когува, 60 - Роотсикюла, 61 - Потсепа, '62 - Лавассааре, 63 - Кыльтси, $64-$ Круузимяэ, 65 - Тылла, 66 - Саарепеэди, $67-$ Супсимари, 68 - Кярстна, 69 - Холдре, 70 - Воола, 71 - Иоости, 72 - Кооза III, 73 - Принги, $74-$ Ресту, 75 - Марьямяэ, 76 - Нуттьмяэ, 77 - Реола, 78 - Сууремяэ, 79 - Постисааре, 80 - Саверна, 81 - Меэкси, 82 - Лауга, 83 - Лоози, 84 - Пюссапалу, 85 - Ногопалу, 86 - Кельби, 87 - Краби.

сжатии в цилиндре и истираемости в полочном барабане. В большинстве месторождений (19) талечник марки И-II удовлетворяет требованиям дробимости при сжатии в цилиндре лишь марке Др16 или Др24. Истираемость в образцах одного карьера колеблется обычно в небольших пределах (табл. 4).

В отличие от показателей дробимости при сжатии в цилиндре показатели истираемости гравийно-галечных отложений менее чувствительны к изменению их петрографического состава.

На территории республики можно четко выделить два района, где показатели истираемости гравийно-галечного материала сравнительно низки и доминируют отложения марки И-III и И-IV (рис. 2). Один из них расположен в Северо-Восточной Эстонии и совпадает с восточной частью зоны I по дробимости, охватывая целиком сланцевый бассейн. Качество травийно-галечного материала здесь понижено из-за обильного скопления в отложениях обломков горючих сланцев, содержание которых местами доходит до. 15-20\% (Раукас, 1978).

Второй район распространения отложений повышенной истираемости (И-III, И-IV) расположен в восточной части о-ва Сааремаа. Чем объяснить бо́льшую истираемость галечника в восточной части острова по сравнению с западной, пока не ясно. Известно только то, что Восточно-Сааремааские гляциальные травийно-галечные отложения сформированы в основном до паливереской стадии последнего оледенения, а Западно-Сааремааские - во время и после этого. Имеющиеся в нашем распоряжении данные не подтверждают выводов Э. Кяппа (Кӓрра, 1934) о том, что на о-ве Сааремаа распространены наилучшие по качеству гравийно-галечные отложения Эстонии.

За пределами двух вышеназванных районов месторождения гравийно-галечного материала с отклонениями от средних показателей истираемости (И-I или И-IV) распределены на территории республики хаотически и не могут быть объединены в какие-либо районы или зоны. Наименышая истираемость (потеря массы 19,0-19,1\%=И-I) определена для образцов из карьера Суурепси (1) на Қыпуском п-ове острова Хийумаа, где добываются переработанные водами Балтийского моря гравийно-галечные отложения радиального оза.

Морозостойкость отложений 68 карьеров из 71 изученного в ЭССР $(95,8 \%)$ удовлетворяет требованиям марки Мрз25 (рис. 3). Низкой маркой морозостойкости (Мрз15) отличаются отложения двух карьеров Западной Әстонии - Питсалу (29) и Лигема (4), а также карьера Рыуде (23) на о-ве Хийумаа, Имеющиеся данные не позво- 


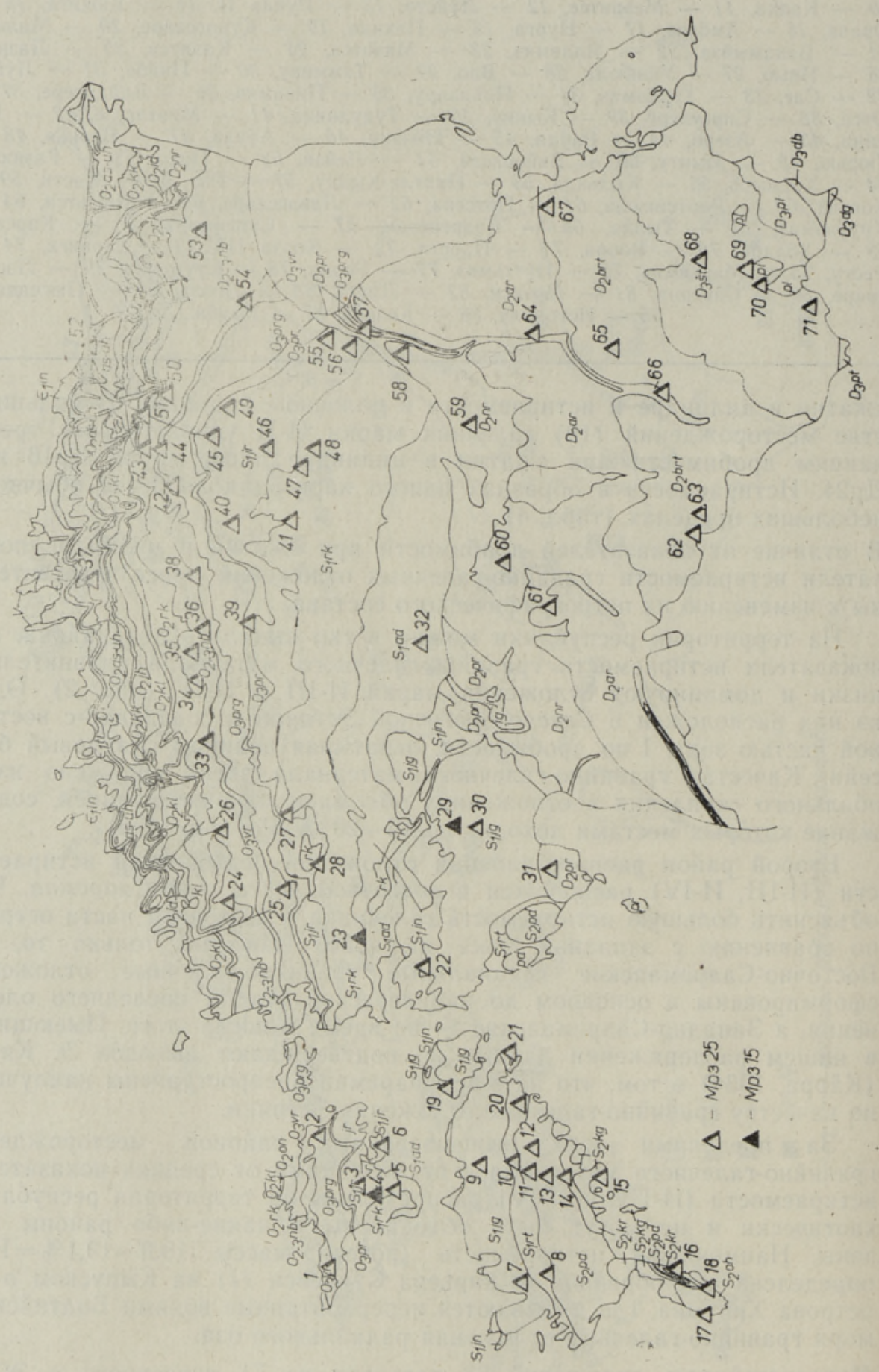


Рис. 3. Схема расположения изученных карьеров по морозостойкости крупнообломочной фракцин. Карьеры: 1 - Суурепси, 2 - Партси, 3 - Мяннамаа, 4 - Лигема, 5 - Муда, 6 - Кассари, 7 - Абула, 8 - Варкья, 9 - Лейзи, 10 - Тика, 11 - Реэкюла, 12 - Уссиотса, 13 - Кыльяла, 14 - Пихтла-Кынну, 15 - Касти, 16 - Вийеристи, 17 - Тюрью, 18 - Мынту, 19 - Когува, 20 - Кыйгусте, 21 Кюбассааре, 22 - Кинкси, 23 - Рыуде, 24 - Яннимаа, 25 - Калда, 26 - Руйла II, 27 - Кюкита, 28 - Меэритсе, 29 - Питсалу, 30 - Лавассааре, 31 - Потсепа, 32 - Круузимяэ, 33 - Пахкла, 34 - Мардимяэ, 35 - Вахелаане, 36 - Куриссааре, 37 - Соосилла, 38 - Малева, 39 - Ванамыйза, 40 - Мяэотса, 41 Калитса, 42 - Лазила, 43 - Раквере, 44 - Инью, 45 - Уникюла, 46 - Таммику, 47 - Пийбе, 48 - Луйге, 49 - Вескимяэ, 50 - Сае, 51 - Мыдрику, 52 - Азери, 53 - Ийзаку, 54 - Тудулинна, 55 - Кынну, 56 - Сиргувере, 57 - Отса, 58 Вайдавере, 59 - Лаэва, 60 - Саарепеэди, 61 - Хеймтали, 62 - Холдре, 63 Воола, 64 - Реола, 65 - Постисааре, 66 - Марьямяэ, 67 - Меэкси, 68 - Лауга, 69 - Пюссапалу, $70-$ Ногопалу, 71 - Краби.

ляют выделить районы гравийно-галечных отложений, показатели морозостойкости которых существенно отличались бы от показателей соседних районов. В то же время некоторые месторождения отложений марки Мрз50 и больше, вероятно, не выяснены, поскольку в строительстве автомобильных дорот в условиях нашей республики требуется материал марки не выше Мрз25, и поэтому испытание галечника проводилось в лаборатории только до 25 циклов попеременного замораживания и оттаивания.

\section{Выводы}

Физико-механические свойства гравия и галечника предопределены главным образом петрографическим составом отложений, который, в свою очередь, зависит от состава исходных отложений и пород. Поэтому изменения физико-механических свойств (в особенности, дробимость при сжатии в цилиндре) гравийно-галечных отложений Эстонской ССР носят территориальный характер. Несомненно, на физикомеханические свойства гравия и галечника оказали влияние также флювиальная транспортировка и морская абразия отложений, в ходе которых крупные фракции обогатились обломками устойчивых, а мелкие - обломками неустойчивых пород. Однако генетические различия между отложениями разных типов (по физико-механическим свойствам) требуют выяснения на основе более обширного фактического материала.

\section{Л ИТЕРА Т Р А}

ГОСТ 8268-74. Гравий для строительных работ. ГК СМ СССР по делам строительства. М., 1977.

ГОСТ 8267-75. Щебень из естественного камня для строительных работ. ГК СМ СССР по делам строительства. М., 1975.

Раукас А. В., Ряхни Э. Э., Мийдел А. М. Краевые ледниковые образования Северной Әстонии. Таллин, 1971.

Раукас А. В. Плейстоценовые отложения Эстонской ССР. Таллин, 1978.

Käppa, E. Maanteede looduslikke ehitusmaterjale Eestis. - Tehnika Ajakiri, 1934, 5/6, $80-87$.

Lepp, E., Meschin, A. Kohalike kivimaterjalide kasutamisvōimalusi teedeehituses. Tallinn, 1971 .

Opik, A. Risti-Palivere otsmoreenist, ning ühest Läänemaa geoloogilisest probleemist. Eesti Loodus, 1936, 2, 53-54.

Тартуский государственный университет

Поступила в редакцию

Министерство автотранспорта

12/XI 1982

и. шоссейных дорог Эстонской ССР 


\section{EESTI NSV KRUUSVEERISTIKE JÄMEFRAKTSIOONI FOOSIKALIS-MEHAANILISED OMADUSED}

Eesti NSV valdavalt iluvioglatsiaalsete kruusveeristike jämefraktsiooni (40-70 $\mathrm{mm})$ füüsikalis-mehaanilisi omadusi on iseloomustatud teimimisel saadud tugevus-, kuluvusja külmakindlusmargi põhjal. Füüsikalis-mehaanilised omadused sổltuvad otseselt uuritava fraktsiooni kivimilisest koostisest, mille määravad lähtekivimite ja setete koostis. Kõige selgemini on jälgitav seos lähtekivimite litoloogilise ja kruusveeristike kivimilise koostise ning vastava purdmaterjali tugevus- ja kuluvusmargi vahel. Et lähtekivimite ja setete omadused ja koostis piirkonniti varieeruvad, on ka purdsetete jämefraktsiooni füüsikalis-mehaaniliste omaduste muutumisel eelköige territoriaalne iseloom. Eestis leidub kőige rohkem tugevusmargile Дp16 vastavat kruusveeristikku (45,9\% uuritud karjääridest), ligikaudu vőrdselt on marke Дp12 (27,8\%) ja Др24 $(24,6 \%)$. Tugevusmargi alusel on eristatud 7 leiukohtade vööndit või rajooni (joon. 1).

Kulumiskindluse seisukohast rahuldavad meie kruusveeristikud valdavalt markide И-II $(64,4 \%)$ ja И-III $(28,7 \%)$ nõudeid. Kuluvusmargi alusel on võimalik eristada Kirde-Eesti ja Ida-Saaremaa suhteliselt väikese kulumiskindlusega jämepurdsetete levikuala (margid И-III ja И-IV).

Proovide külmakindlus on määratud ainult margini Мрз25, sest Eesti tingimustes pole kvaliteetsem materjal nõutav. Selle margi nõudeid rahuldab $95,8 \%$ uuritud leiukohtadest kaevandatavast materjalist.

\section{KALM, A. MESCHIN}

\section{PHYSICO-MECHANICAL PROPERTIES OF THE COARSE FRACTION OF PEBBLY-GRAVEL DEPOSITS OF THE ESTONIAN SSR}

Physico-mechanical properties of the coarse fraction of pebbly-gravel deposits are characterized according to the results of pressure resistance, spending resistance and frost resistance tests. Physico-mechanical properties of the pebbly-gravel deposits depend directly upon the petrographical composition of the tested fraction, which is predetermined by the composition of the primary rocks and deposits. Such dependence is clearly observed between the petrographical composition of the pebbly-gravel deposits and the pressure resistance showings. Whereas the properties of the primary rocks and deposits are subjected to regional changes, the physico-mechanical properties of the coarse-fractioned deposits are likewise of a territorially changing character. The dependence of the physico-mechanical properties upon the genetic types of the pebbly-gravel deposits requires more detailed investigation.

The most wide-spread pebbly-gravel deposits belong to the pressure resistance classes Др16 (45.9\% of explored pits), Др12 (27.8\%) and Др24 $(24.6 \%)$. By pressure resistance showings we can draw up seven regions of pebbly-gravel pits of different quality classes in the Estonian SSR.

As for the spending resistance, the prevailing deposits satisfy mostly the И-II class conditions $(64.4 \%$ of explored pits); the И-III class deposits $(28.7 \%)$ are not so widely spread. By the spending resistance showings it is possible to differentiate two regions, where the dominating material is of a relatively low quality (classes И-III and И-IV). These regions are represented by the north-eastern part of Estonia and the eastern part of Saaremaa Island.

The frost resistance level is determined only up to the class $\mathrm{Mp}_{2} 25$, because there is no need for the pebbly-gravel material of better quality in the Estonian SSR. $95.8 \%$ of the explored pebbly-gravel occurrences contain deposits which satisfy the Mp325 class conditions. At present it is impossible to divide the pebbly-gravel deposits into separate regions by frost resistance showings. 